\title{
The Effect of Solution Annealing on the Property of Passivated Surface in CF8 Stainless Steel
}

\author{
Yong Soo Kim', Yu Jin Kang², Sung Joon Pak ${ }^{3}$ and Dong Jun Lee ${ }^{1}$ \\ ${ }^{1}$ Department of Nuclear Engineering, Hanyang University, Korea \\ ${ }^{2}$ KHNP-CRI, Korea \\ ${ }^{3} \mathrm{KITECH}$, Korea
}

ISSN: 2578-0255

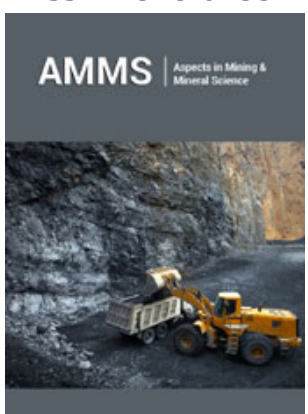

*Corresponding author: Yong Soo Kim, Department of Nuclear Engineering, Hanyang University, Korea

Submission: 䤉 October 30, 2019

Published: : November 13, 2019

Volume 4 - Issue 1

How to cite this article: Yong Soo Kim, Yu Jin Kang, Sung Joon Pak, Dong Jun Lee. The Effect of Solution Annealing on the Property of Passivated Surface in CF8 Stainless Steel. Aspects Min Miner Sci.4(1). AMMS.000578.2019.

DOI: 10.31031/AMMS.2019.04.000578

Copyright@ Yong Soo Kim, This article is distributed under the terms of the Creative Commons Attribution 4.0 International License, which permits unrestricted use and redistribution provided that the original author and source are credited.

\begin{abstract}
The surface characteristics of CF8 stainless steel materials for shell mold cast and investment cast were studied, including surface composition, roughness and reflectivity. We report their changes are governed by the solution annealing, casting and passivation treatment. As for the surface composition, Chromium (Cr) portion decreased initially but showed increasing tendency at time passed in passivated shell mold cast. However, nickel (Ni) portion increased initially but revealed decreasing tendency at time passed. This implies the surface film becomes the chromium-rich oxide phase at optimum condition. The optical reflectivity of solution annealed and passivated surface increased by $16 \%$ compared to the basis metal case. When the optimum chemical passivation was applied, the surface roughness showed the lowest value in shell mold cast. This may indicate that the corrosion resistance of CF8 material can be improved by solution annealing followed by optimized chemical passivation.
\end{abstract}

Keywords: CF8 stainless steel; Reflectivity; Roughness; Corrosion resistance

\section{Introduction}

In recent years, there have been considerable interests in the development of techniques that allow examination of mechanical material surfaces [1,2]. It has been known that it is necessary to add $\sim 13 \% \mathrm{Cr}$ in order to make FeCr alloys corrosion-resistant. However, it is not understood why this amount is critical for prevention of corrosion under conditions where the metal is already covered with an oxide film (either an air-formed film or a passive film). When the ferric oxide component of the film is reduced to ferrous oxide and dissolves away, the exposed underlying iron corrodes. A synchrotron-based spectroscopic method, or X-ray absorption near edge structure (XANES) is able to give information on both the valence electron state of species in passive films, and the amount of each element with monolayer resolution during film formation and dissolution. Recent investigations have shown that the passivation in mildly acidic solutions results in no detectable dissolution of $\mathrm{Cr}$, but a small quantity of Fe is lost. During reduction of the oxide, the Fe loss appears to increase significantly below about $13 \%$ Cr. These measurements are being used to test the hypothesis that the extent of reactivation is controlled by the $\mathrm{Cr}$ content of a stoichiometric passive oxide layer that forms under a Cr-rich porous layer resulting from passivation [3]. Newman and co-workers have found a different critical threshold at $17 \% \mathrm{Cr}$ for passivation of oxide-free stainless steel surfaces, which they have modeled using an approach based on the percolation theory [4]. Both the value and sharpness of the threshold were verified using another synchrotron-based technique, the X-ray microprobe [5]. Rather than making a whole series of samples with compositions close to the $17 \%$ threshold, a single thin film sample was sputter-deposited with a continuous lateral variation in $\mathrm{Cr}$ content by sputtering from adjacent $\mathrm{Fe}$ and $\mathrm{Cr}$ targets to give a linear variation in composition, with a resolution of $\sim 0.01 \%$. The crystallinity of passive films can also be correlated with the passivity of FeCr alloys. Using in situ STM, Ryan et al. [6] found that the passive film on a sample containing $13.8 \% \mathrm{Cr}$ showed long range crystalline order, whereas that on a sample with $16.5 \% \mathrm{Cr}$ was more disordered. According to the model, the passive film formed from an alloy with a lower $\mathrm{Cr}$ content is more open, so it can crystallize more readily. We study the film passivation effects on surface properties such as 
reflectivity in materials of shell mold cast CF8 stainless steel Elbow fittings. When the optimum chemical passivation treatment was applied, its corrosion rate showed the lowest value. Consequently, it is suggested that the corrosion resistance of SSC13 50A Elbow fittings can be improved in relationship to the reflectivity of passive film [7-22].

\section{Experimental}

The material used in our study was a shell mold cast CF8 stainless steel (SS) and its chemical composition is shown in Table 1. Shell mold cast CF8 SS samples were solid solution annealed at $1393 \mathrm{~K}\left(1120{ }^{\circ} \mathrm{C}\right)$ for 10 minutes and then water-quenched, producing average grain size of $50 \mu \mathrm{m}$. Table 2 shows the specimen conditions used for the corrosion tests. The six distinct specimens numbered 1, 2, 3, 4, 5 and 6, were tested. They were then immersed in a test solution composed of $65 \% \mathrm{HNO}_{3}$ at $150{ }^{\circ} \mathrm{C}$ for 48 hours, and their weight loss \% measurements were accomplished using the ASTM A 262 method. The centers of surfaces exposed to the test solution were observed by a scanning electron microscope (JSM6701F).

Table 1: Chemical composition of the CF8 austenitic stainless steel (wt. \%).

\begin{tabular}{|c|c|c|}
\hline Elements & Measured & ASTM A743 \\
\hline $\mathrm{C}$ & 0.0755 & $0.08 \max$ \\
\hline $\mathrm{Si}$ & 1.2989 & $2.00 \max$ \\
\hline $\mathrm{Mn}$ & 1.11 & $1.50 \max$ \\
\hline $\mathrm{P}$ & 0.02763 & $0.040 \max$ \\
\hline $\mathrm{S}$ & 0.00225 & $0.040 \max$ \\
\hline $\mathrm{Ni}$ & 8.26375 & $8.00 \sim 11.00$ \\
\hline $\mathrm{Cr}$ & 18.225 & $18.00 \sim 21.00$ \\
\hline
\end{tabular}

Table 2: Conditions of specimens for the tests.

\begin{tabular}{|c|c|c|}
\hline $\begin{array}{c}\text { Specimen } \\
\text { No. }\end{array}$ & Casting conditions & Treatment conditions \\
\hline 1 & Shell mold casting & Natural passivation \\
\hline 2 & Shell mold casting & $\begin{array}{c}\text { Solution annealing \& natural pas- } \\
\text { sivation }\end{array}$ \\
\hline 3 & Shell mold casting & $\begin{array}{c}\text { Solution annealing \& } 10 \text { second } \\
\text { chemical passivation }\end{array}$ \\
\hline 4 & Shell mold casting & $\begin{array}{c}\text { Solution annealing \& } 30 \text { second } \\
\text { chemical passivation }\end{array}$ \\
\hline 5 & Shell mold casting & $\begin{array}{c}\text { Solution annealing \& } 60 \text { second } \\
\text { chemical passivation }\end{array}$ \\
\hline 6 & Investment casting & Natural passivation \\
\hline
\end{tabular}

\section{Results and Discussion}

We evaluated solution annealed samples which were chemically passivated with respect to those naturally passivated for corrosionresistant shell mold cast and investment cast. As shown in Figure 1, all specimens show weight loss while the specimen No. 3 and No. 6 show negligible ones. This indicates the formation of enhanced film protection. The resistance to corrosion increased by more than a factor of two when the solution annealing and chemical passivation were applied [23]. Figure 2 shows surface roughness of the different specimen. We find that the specimen with negligible weight loss as particularly seen in the investment cast specimen No. 3 and No. 6, produce reduced roughness. This leads to the close relation (Figure 3 ) between surface roughness and film passivation. Figure 3 shows the change of surface composition of specimens. It is revealed that the specimen No. 3 shows the lowest chromium content as $17.2 \%$, possibly due to the depletion of $\mathrm{Cr}$ on the surface, forming protective film. As chemical passivation time increases, nickel on the surface could be dissolved due to excessive chemical reactions. Figure 4 shows the changes in optical reflectivity at visible wavelength, which were measured by the spectrophotometer for the test specimen. The reflectivity change was measured with respect to that for basis metal. The results show that, while the solution annealing treatment increased the reflectivity of the shell mold cast specimen, natural passivation increased the reflectivity of the investment cast specimen.

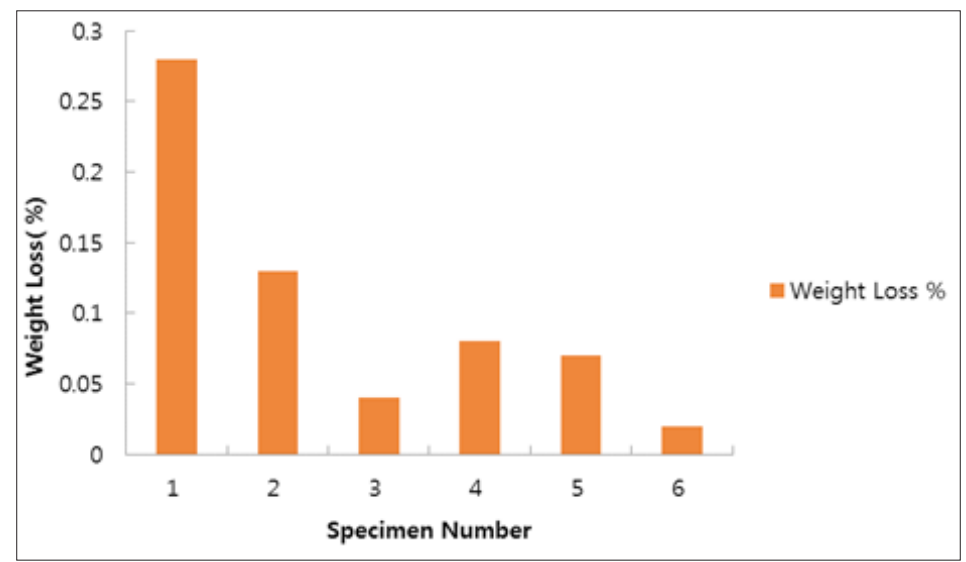

Figure 1: Weight loss (\%) for the different specimens for corrosion test. 




Figure 2: Surface roughness of different specimens.

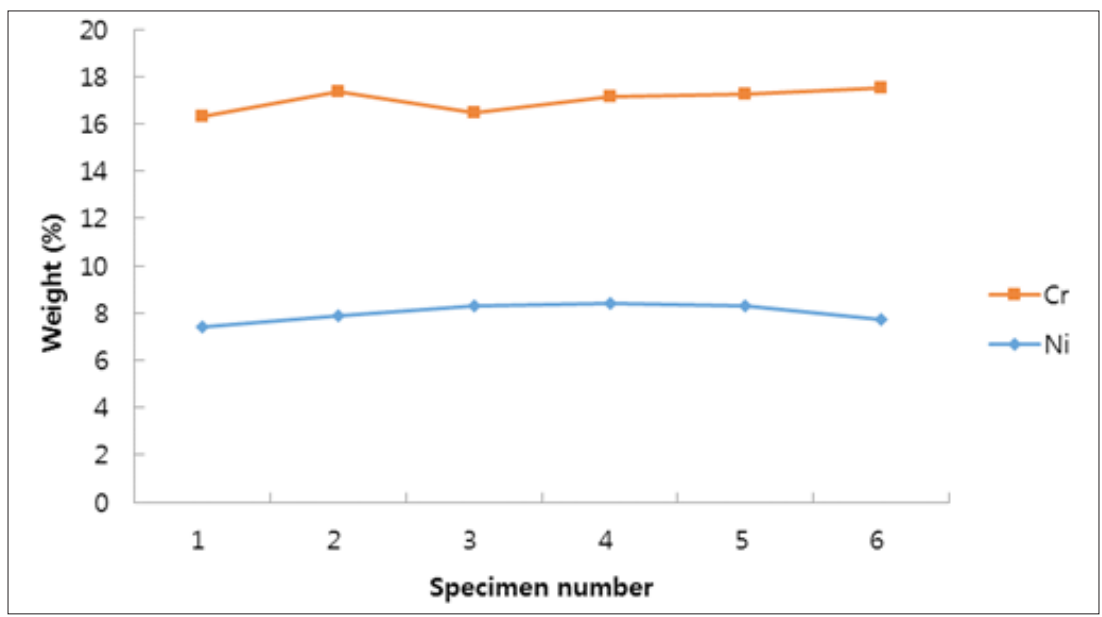

Figure 3: Surface composition of CF8 stainless steel for different specimen

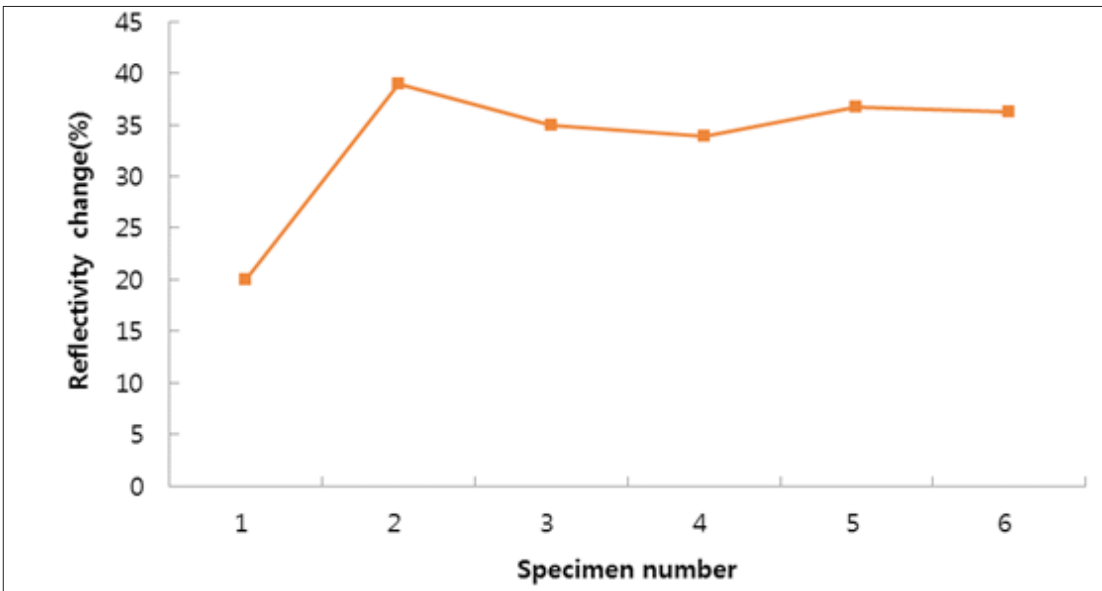

Figure 4: Change in optical reflectivity of the different specimen at visible wavelength.

\section{Conclusion}

The corrosion resistance of the CF8 stainless steel was affected by roughness and reflectivity of the material surface. The resistance to corrosion increased by more than a factor of two when the solution annealing and chemical passivation were applied. While all tested specimens showed some susceptibility to chemical corrosion, the specimen No. 1 showed large number of weight loss indication. This suggested a generalized attack on the surface. The reflectivity of solution annealed, and passivated surfaces measured by SD-4000 spectrophotometer was increased from basis metal by $16 \%$. When the optimum chemical passivation treatment was applied, its corrosion ratio and surface roughness showed the 
lowest value in shell mold cast. Consequently, it is suggested that the corrosion resistance of CF8 material can be improved by the roughness and reflectivity of passive film on the surface.

\section{Acknowledgment}

This work was supported by KHNP(www.khnp.co.kr). [Project Name: K-CLOUD].

\section{References}

1. Davenport AJ (1998) In Situ corrosion studies. Electrochem Soc 29: 2829

2. Wenjie Xia, Sinan Keten (2015) Interfacial stiffening of polymer thin films under nanoconfinement. Extreme Mechanics Letters 4: 89-95.

3. Davenport AJ, Newman RC, Oblonsky LJ, Ryan MP (1996) In surface oxide films. In: Bardwell JA (Ed.), PV 96-18, The Electrochemical Society Proceedings Series, Pennington, NJ, US.

4. Sieradzki K, Newman RC (1986) A percolation model for passivation in stainless steels. J Electrochem Soc 133(9): 1979-1980.

5. Davenport AJ, Newman RC, Ryan MP, Simmonds MC, Sutton SR, et al. (2001) In Situ synchrotron x-ray microprobe studies of passivation thresholds in Fe-Cr alloys. J Electrochem Soc 148(6): B217-B221.

6. Ryan MP, Newman RC, Thompson GE (1994) Atomically resolved STM of oxide film structures on $\mathrm{Fe}-\mathrm{Cr}$ alloys during passivation in sulfuric acid solution. J Electrochem Soc 41(12): L164-L165.

7. Stonawska Z, Svoboda M, Sozanska M, Kristková M, Sojka J, et al. (2006) Structural analysis and intergranular corrosion tests of AISI 316L steel. J Microsc 224(1): 62-64.

8. Terada M, Saiki M, Costa I, Padilha AF (2006) Microstructure and intergranular corrosion of the austenitic stainless steel 1.4970. J Nucl Mater 358: 40-46.

9. Weiss B, Stickler R (1972) Phase instabilities during high temperature exposure of 316 austenitic stainless steel. Metal Trans 3(4): 851-866.

10. Barcik J (1988) Mechanism of $\sigma$-phase precipitation in $\mathrm{Cr}-\mathrm{Ni}$ austenitic steels. Mater Sci Technol 4(1): 5-15.

11. Matula M, Hyspecka L, Svoboda M, Vodarek V, Dagbert C, et al. (2001) Intergranular corrosion of AISI 316L steel. Mater Charact 46(2-3): 203210.
12. Padilha F, Rios PR (2002) Decomposition of austenite in austenitic stainless steels. ISIJ Int (Japan) 42(4): 325-327.

13. Zingales A, Quartarone G, Moretti G (1985) Sigma phase intergranular corrosion effects in austenitic welds containing ferrite. Corrosion 41(3): 136-141.

14. Ganesan V (1998) Corrosion of annealed AISI 316 stainless steel in sodium environment. J Nucl Mater 256(1): 69-77.

15. Lin D, Wu W, Lin CH, Hsieh HH (2001) The effect of aging on the intergranular corrosion of a $24 \mathrm{Cr}-14 \mathrm{Ni}-0.7 \mathrm{Si}$ stainless steel welding in architecture. Steel Res 72(7): 277-280.

16. Amirthalingam R, Shaikh H, Anita T, Poonguzhali A, Manohar P, et al. (2006) Effect of high temperature ageing on the corrosion behaviour of nitrogen-added AISI type 316L stainless steel. T Indian I Metals 59: 271-282.

17. Newman RC, Shahrabi T (1987) The effect of alloyed nitrogen or dissolved nitrate ions on the anodic behavior of austenitic stainless steel in hydrochloric acid. Corr Sci 27(8): 827-838.

18. Rhodes GO, Conway JJ (1996) High nitrogen austenitic stainless steels with high strength and corrosion resistance. JOM 48(4): 28-31.

19. Ningshen S, Mudali UK, Amarendra G, Golapan P, Dayal RK, et al. (2006) Hydrogen effects on the passive film formation and pitting susceptibility of nitrogen containing type 316L stainless steels. Corr Sci 48(5): 11061121.

20. Terada M, Escribab DM, Costaa I, Morrisc EM, Padilhab AF (2008) Investigation on the intergranular corrosion resistance of the AISI $316 \mathrm{~L}(\mathrm{~N})$ stainless steel after long time creep testing at $600^{\circ} \mathrm{C}$. Materials Characterization 59(6): 663-668.

21. Padilha F, Escriba DM, Morris EM, Rieth M, Klimenkov M (2007) Precipitation in AISI $316 \mathrm{~L}(\mathrm{~N})$ during creep tests at 550 and $600{ }^{\circ} \mathrm{C}$ up to 10 years. J Nucl Mater 362(1): 132-138.

22. Kim KJ, Ju H, Moon YD, Hong JH, Pak SJ (2016) Effect of the solution annealing and chemical passivation followed by aging on the corrosion of shell mold cast CF8 stainless steel. Metallurgical and Materials Transactions A 47(10): 4979-4982.

23. Kim KJ, Lim SG, Pak SJ (2015) Effects of the solid solution heat treatment on the corrosion resistance property of SSC13 cast alloy. Corrosion Science and Technology 14(2): 93-98. 